DOI: $10.14451 / 2.161 .7$

\title{
КОНКУРЕНТОСПОСОБНОСТЬ РОССИЙСКИХ УНИВЕРСИТЕТОВ И ЭКСПОРТ ОБРАЗОВАНИЯ: ОСОБЕННОСТИ ПРАВОВОГО РЕГУЛИРОВАНИЯ И ОТБОРА ПРОГРАММ РАЗВИТИЯ"
}

\author{
(c) 2021 Щукина Татьяна Владимировна \\ доктор юридических наук, доцент, заведующая кафедрой прикладного права \\ МИРЭА - Российский технологический университет, Россия, Москва \\ профессор Липецкого филиала РАНХИГС, Россия, Липецк
}

Предметом настоящей статьи выступает исследование правового регулирования стратегий конкурентоспособности российских университетов в условиях научно-технологического развития и возможности экспорта российского образования. Тема статьи отражает вопросы правового регулирования отбора программ академического лидерства как инструмента взаимодействия государства и университетов с целью стратегического развития государства. Целью настоящей статьи является выявление особенностей в правовом регулировании условий конкурентоспособности российских университетов на современном этапе социально-экономического и научно-технологического развития, места и роли государства в этом процессе. Методологию данной работы составили сравнительный, формально-юридический, аналитический методы. Результаты работы - это формулирование роли и содержания оценки программ развития университетов по программе стратегического академического лидерства «Приоритет-2030». Область применения результатов работы включает в себя правовое обеспечение государственной политики стратегического планирования в сфере системы высшего образования.

Ключевые слова: программа стратегического академического лидерства «Приоритет-2030», конкурентоспособность университета, отбор программ развития, экспорт высшего образования, научнотехнологическое развитие

Согласно Правилам, утвержденным Постановлением Правительства РФ от 13 мая 2021 г. № 729, производится отбор университетов, разработавших уникальные программы собственного развития. Программы развития университетов по замыслу законодателя должны быть ориентированы на реализацию нескольких важных направлений стратегического развития страны. Это: 1) включение российских вузов в реализацию национальных целей развития Российской Федерации на период до 2030 года, 2) «сбалансированное пространственное развитие страны, обеспечение доступности качественного высшего образования в субъектах Российской Федерации» [1].

Подобные гранты предоставляются в виде субсидий из федерального бюджета на программы развития вузов [1]. Грант состоит из двух частей: базовой и специальной. Базовая часть гранта предоставляется «на увеличение вклада университета в социально-экономическое развитие субъектов Российской Федерации и реализацию новых творческих, социально-гуманитарных проектов» [1]. Данная часть гранта призвана сти- мулировать по большей части вузы субъектов Российской Федерации включаться в процесс создания инновационных образовательных продуктов, привлекать молодежь в социальные проекты, необходимые для соответствующего региона, и приумножать базу научно-технологического прогресса. Становиться лидерами среди вузов собственного субъекта Российской Федерации и в целом по стране. Грант предполагает включение университета в рейтинг лучших вузов России. «Минимальный размер базовой части гранта составляет 100 млн. рублей в год» [1].

Специальная часть гранта предполагает отбор университетов в двух форматах: а) «исследовательское лидерство - проведение прорывных научных исследований и создание наукоемкой продукции и технологий, наращивание кадрового потенциала сектора исследований и разработок; б) территориальное и (или) отраслевое лидерство - социально-экономическое развитие территорий, укрепление кадрового и научнотехнологического потенциала организаций реального сектора экономики и социальной сферы» [1].

\footnotetext{
* статья подготовлена в рамках гранта РФФИ 19-011-00959 «Моделирование экспорта высшего образования в рамках новых стратегий публичного управления в Российской Федерации» 2019-2021 г.г.
} 
Предоставление специальной части гранта осуществляется Советом по поддержке программ развития образовательных организаций высшего образования по реализации программы стратегического лидерства (далее - Совет). Это постоянно действующий совещательный орган, образованный в целях реализации программы «Приоритет-2030» [2]. Кроме того, Совет в целом участвует в рассмотрении вопросов, связанных с развитием вузов, претендующих и получающих специальную часть гранта.

Специальная часть гранта зависит от большого набора показателей, включенных в формулу по расчету размера специальной части гранта. Например, «общего размера специальной части гранта, запланированного на очередной финансовый год» [1], от «общего числа университетов - участников программы «Приоритет-2030», прошедших оценку Совета» [1], от коэффициента, установленного «для университета - получателя предельного размера специальной части гранта» [1], и других показателей, Коэффициенты, рассчитываемые Советом, зависят от результатов рейтингования университетов.

Ранжирование университетов проводится Советом на основании рассмотрения и оценки проектов программ развития университетовучастников «Приоритет-2030» по следующим критериям [3].

Первый критерий - амбициозность целей и результатов программы развития университетаконкурсанта. Соответствие данному критерию, по мнению авторов, носит обширный характер. Университетский проект должен опираться на национальные цели развития Российской Федерации на период до 2030 года [4], Стратегию НТР [5], «стратегии социально-экономического развития субъектов Российской Федерации и (или) отраслевых документов стратегического планирования» [6]. Образовательная организация обязана провести разработку своего проекта согласно требованиям минимум двух документов стратегического планирования и «внедриться» В область государственной политики в сфере стратегического планирования. Анализ указанных нормативных правовых актов вызывает правомерный вопрос: «Сколько национальных целей развития Российской Федерации и направлений Стратегии НТР должна включать в себя программа вуза - конкурсанта? Какой охват целей и результатов проекта вуза будет соответствовать критерию - амбициозность?».

Второй критерий - академическое признание и потенциал вуза, в том числе с учетом результатов реализации программы государственной поддержки, предусмотренной постановлением Правительства Российской Федерации от 16 марта 2013 г. № 211 для университетов, ранее получавших государственную поддержку в рамках указанного нормативного правового акта.

Это так называемый проект 5-100, завершившийся в 2020 году, и в котором принял участие двадцать один российский университет. Получается, что второй критерий предоставляет 21 университету Российской Федерации определенные преимущества перед другими конкурсантами и возможность получения вузов, принимавших участие в проекте 5-100, получить дополнительные баллы в общей сумме баллов оценки своей программы развития.

Третий критерий - степень проработанности программы развития университета - конкурсанта. В Правилах отсутствуют примерные показатели оценки проекта университета по третьему критерию. В соответствии с пунктом 6 Правил, разработка и утверждение методических рекомендаций Министерством науки и высшего образования РФ возможны по реализации мероприятий, которые университеты предложат в своих программах развития. Думается, что есть необходимость в разработке общих методических рекомендаций, касающихся самой программы Приоритет 2030 и рассматриваемых Правил. В Правилах отсутствуют примерные показатели оценки проекта университета по четвертому критерию, равно как и теоретическое понимание понятий «творческий» и «социально-гуманитарный проект»; нет краткого перечня работодателей и их объединений.

Четвертый критерий - реализация творческих и социально-гуманитарных проектов и взаимодействие университета с органами государственной власти регионов, ОМС, работодателями и их объединениями, а также с хозяйствующими субъектами в регионах.

Исходя из толкования четвертого критерия оценки, он должен включать в общей совокупности:

a) участие университета одновременно и в творческих, и в социально-гуманитарных проектах;

б) взаимодействовать с органами всех уровней публичной власти, и с работодателями и их объединениями, и с организациями, производящими материальные и нематериальные блага, за исключением банковских организаций и участников биржевой торговли конкретного субъекта Российской Федерации. 
В Правилах отсутствуют примерные показатели оценки проекта университета по четвертому критерию, равно как и теоретическое понимание понятий «творческий» И «социальногуманитарный проект». Относительно конкретизации в Правилах термина «организация реального сектора экономики в субъектах Российской Федерации» также возникает дилемма. Сама категория «реальный сектор экономики» является достаточно общей.

Реальный сектор экономики в научных исследованиях видится следующим образом: «реальный сектор экономики может выглядеть следующим образом: реальный сектор - сектор, в котором создается валовой внутренний продукт. Он включает предприятия и организации сектора нефинансовых корпораций, где воспроизводятся все товары и услуги (кроме услуг финансового посредничества), реализуемые на свободном рынке. Основу реального сектора экономики составляет производство промышленной и сельскохозяйственной продукции, а торговая деятельность является его неотъемлемой частью» [7]. Поэтому необходимо обозначить примерный перечень подобных организаций реального сектора экономики или разъяснить, что понимается в Правилах под этим понятием.

Конечно же, краткое перечисление форм взаимодействия университета со всеми выше упомянутыми субъектами необходимо представить, по мнению авторов, в возможном проекте Методических рекомендаций по разработке проектов программ развития университетов-участников «Приоритет-2030».

Пятый критерий - модернизация системы управления вузом и его взаимодействие с другими участниками консорциума, который предназначен для реализации сетевых образовательных программ и научных проектов, внедрения инновационных решений. По данному критерию приведены в Правилах кратко показатели, на которые могут ориентироваться члены Совета, в процессе оценки проекта университета. К ним относится «оценка долгосрочной стратегии развития консорциума и деятельности управляющих органов консорциума (консорциумов)» [1]. Касательно понятия консорциумов в пункте 7 Правил закрепляется, что в программах вузов дополнительно «предусматривается реализация мероприятий с формированием консорциумов - объединений, в том числе без образования юридического лица, с другими университетами и (или) научными организациями, независимо от их ведомственной принадлежности, и при необходимости с иными организациями на основании соглашений о взаимодействии» [1]. Получается, что под консорциумом понимается одновременно научное и образовательное объединение университетов и (или) научных учреждений с возможностью совместного использования материально-технологической базы в целях взаимного сотрудничества. В отличие от шестого критерия Правил в данном случае слияние и (или) присоединение вузов и (или) научных учреждений не предполагается, включая утрату юридической самостоятельности.

Шестой критерий - «реорганизация в форме слияния (присоединения) с другими образовательными организациями высшего образования и (или) научными организациями (при включении в программу развития университетаконкурсанта мероприятий по реорганизации)» [1]. Этот критерий связан с процессом укрупнения вузов и (или) научных учреждений с точки зрения прекращения деятельности юридического лица (присоединяющегося субъекта или субъектов, объединяющихся в новую организацию). Происходит утрата юридической самостоятельности, структурного и финансового единства либо присоединяющегося участника, либо всех участников, которые впоследствии создадут новое юридическое лицо в виде образовательной организации высшего образования. Насколько эффективно будет воздействие вышеназванного критерия на развитие университетов - покажет время.

Седьмой критерий - «обеспечение условий для формирования цифровых компетенций и навыков использования цифровых технологий обучающихся» [1]. Помимо соответствия критериям оценки программ развития, установленным Правилами, к проектам предъявляется условие об обязательности включения в них отдельных мероприятий по выбору университета. Все мероприятия можно разделить на виды по следующим направлениям:

1) разработка и продвижение творческих и социально-гуманитарных проектов: а) новых творческих и социально-гуманитарных проектов, б) «творческих и социально-гуманитарных проектов с участием университетов, научных и других организаций реального сектора экономики и социальной сферы» [1];

2) подготовка и реализация сетевых образовательных программ ВО, новых ОП ВО и дополнительных профессиональных программ в интересах НТР, в) «продвижение образовательных программ и результатов научно-исследовательских и опытно-конструкторских работ» [1]; 
3) развитие кадрового потенциала и системы мер его поддержки: а) системы ВО, приглашение в вузы ведущих ученых и специалистов-практиков, б) формирование мероприятий по поддержке молодых преподавателей, в) совершенствование научно-исследовательской деятельности в магистратуре, аспирантуре и докторантуре;

4) обеспечение трудоустройства выпускников: трудоустройству выпускников вузов в научных организациях и высокотехнологичных предприятиях;

5) развитие прорывных научных исследований, коммерциализация результатов интеллектуальной деятельности, материальнотехнической и приборной базы университетов: а) трансфер технологий, создание студенческих технопарков и бизнес-инкубаторов, развитие материально-технических условий осуществления образовательной и иной деятельности университетов, б) вовлечение студентов в научноисследовательские, опытно-конструкторские, «инновационные работы и (или) социально ориентированные проекты, а также осуществление поддержки обучающихся» [1];

6) обеспечение экспорта высшего образования и развитие академической мобильности: а) реализация программ внутрироссийской и международной академической мобильности НПР и студентов, «творческих и социальногуманитарных проектов» [1], б) привлечение иностранных граждан для обучения в вузах России и их трудоустройство;

7) реализация цифровых изменений в области подготовки кадров и деятельности университетов, научных организаций в целом: а) подготовка кадров для работы в сфере НТР, б) цифровая трансформация университетов и научных организаций;

8) координация и обеспечение передачи опыта от лучших университетов: а) объединение с университетами и (или) научными организациями; б) «тиражирование лучших практик университета в других университетах, не являющихся участниками программы академического лидерства» [1].

Относительно критерия, касающегося обеспечения экспорта высшего образования. Опрос, проведенный в 2020 году по грантовому исследованию № 9-011-00959 «Моделирование экспорта высшего образования в рамках новых стратегий публичного управления в Российской Федерации» 2019-2021 г.г., показал, что в большей части вузов, в которых учатся или работают респонденты, экспорт образования фрагментарно суще- ствует (рис.1). Причем в отдельных университетах происходит сочетание нескольких направлений экспорта образования. Об отсутствии экспортной практики призналось всего три участника из более ста опрошенных участников. Наиболее распространено в вузах обучение иностранных студентов, программы обмена преподавателями и студентами, а также программы двойных дипломов. Такая форма экспорта образования как обучение или разработка образовательной программы магистратуры и аспирантуры с присвоением ученой степени $\mathrm{PhD}$ не была указана ни одним из опрошенных.

На вопрос «Участвуете ли Вы в процессе экспорта образования? Если да, то в какой форме?» большинство респондентов (79\%) ответило отрицательно. Опрошенные, отвечавшие положительно на данный вопрос, указывали на такие формы участия в процессе экспорта образования как:

- обучение иностранных студентов, в том числе, на английском языке;

- участие в программах академической мобильности;

- стажировка;

- исследовательская работа и обучение за границей;

- участие в летних школах;

- руководство магистерской программы двух дипломов;

- участие в международных и совместных образовательных программах;

- разработка международных модулей в образовательной программе бакалавриата и т.д.

В отдельных случаях респонденты указывают на одновременное участие в нескольких формах экспорта образования.

Немного о тенденциях экспорта образования за рубежом. Стоит отметить об экспансии англоязычных программ магистратуры и бакалавриата и увеличении их количества в Китае и странах Азии. Особенно это прослеживается в таких науках как медицина, педагогика и прикладные науки. Китай усиливает вступительные кампании по привлечению на обучение студентов из африканских стран, пытаясь таким образом занять глобальную часть международного рынка образования. В России же согласно данным анкетирования, большая часть респондентов не задействована в экспортных программах вузов, и, по сути, рынок экспорта образования достаточно однообразный. Следовательно, университетыдрайверы, которые будут реализовывать государственную программу «Приоритет-2030» в каче- 


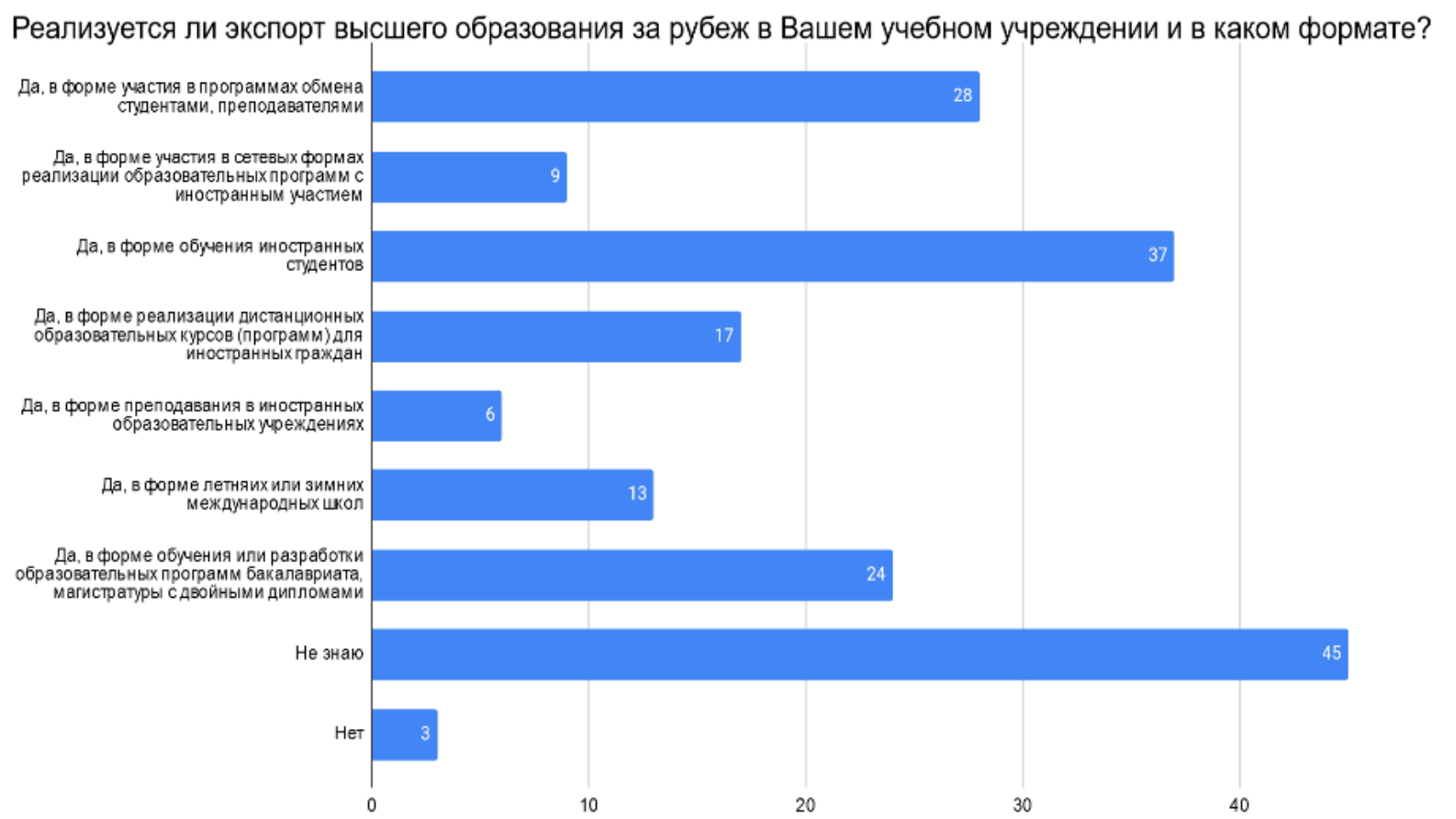

Puc. 1. Виды экспорта высшего образования в университетах

стве условия участия в проекте и его исполнения, луг. Формировать устойчивый интерес у потредолжны разрабатывать и внедрять более активно бителей на международном рынке к образовановые формы экспорта образования, выходить тельным программам не только на английском, на международный рынок образовательных ус- но и на русском языках.

\section{Библиографический список}

1. О мерах по реализации программы стратегического академического лидерства «Приоритет-2030»: Постановление Правительства РФ от 13 мая 2021 г. № 729 // Собр. законодательства Рос. Федерации. 2021. № 22. Ст. 3823.

2. О Совете по поддержке программ развития образовательных организаций высшего образования в рамках реализации программы стратегического академического лидерства «Приоритет-2030»: Постановление Правительства РФ от 13 мая 2021 г. № 730 // Собр. законодательства Рос. Федерации. 2021. № 22. Ст. 3824.

3. О мерах по реализации программы стратегического академического лидерства «Приоритет-2030»: Постановление Правительства РФ от 13 мая 2021 г. № 729 // Собр. законодательства Рос. Федерации. 2021. № 22. Ст. 3823.

4. О национальных целях развития Российской Федерации на период до 2030 года: Указ Президента РФ от 21 июля 2020 г. № 474 // Собр. законодательства Рос. Федерации. 2020. № 30. Ст. 4884; Единый план по достижению национальных целей развития Российской Федерации на период до 2024 года и на плановый период до 2030 года.

5. О Стратегии научно-технологического развития Российской Федерации: Указ Президента РФ от 1 декабря 2016 г. № 642 (с изм. и доп. от 15 марта 2021 г) // Собр. законодательства Рос. Федерации. 2016. № 49. Ст. 6887; 2021. № 12. Ст. 1982.

6. О Стратегии развития информационного общества в Российской Федерации на 2017-2030 годы: Указ Президента РФ от 9 мая 2017 г. № 203 // Собр. законодательства Рос. Федерации. 2017. № 20. Ст. 2901; О Стратегии развития малого и среднего предпринимательства в РФ на период до 2030 г. и плане мероприятий («дорожной карте») по ее реализации: Распоряжение Правительства РФ от 2 июня 2016 г. № 1083-р (с изм. и доп. от 8 декабря 2016 г.) // Собр. законодательства Рос. Федерации. 2016. № 24. Ст. 3549; № 51. Ст. 7426.

7. Балаганский С. П. Реальный сектор экономики как объект экономического анализа // Вестник Саратовского государственного социально-экономического университета. 2012. № 1 (40). С. 2-4. 